\title{
Forecast Grain “Three Quantities” Based on Grey GM $(1,1)$ and Promote the Structural Reform of Grain Supply Side
}

\author{
Bingjun Li, Xiaoxiao Zhu* \\ College of Information and Management Science, Henan Agricultural University, Zhengzhou, China \\ Email: zzlbjun@163.com, *zhu_xiaoxiao113@163.com
}

How to cite this paper: $\mathrm{Li}, \mathrm{B} . J$. and $\mathrm{Zhu}$, X.X. (2018) Forecast Grain "Three Quantities" Based on Grey GM $(1,1)$ and Promote the Structural Reform of Grain Supply Side. Agricultural Sciences, 9, 1432-1443. https://doi.org/10.4236/as.2018.911099

Received: October 17, 2018

Accepted: November 18, 2018

Published: November 22, 2018

Copyright (๑) 2018 by authors and Scientific Research Publishing Inc. This work is licensed under the Creative Commons Attribution International License (CC BY 4.0).

http://creativecommons.org/licenses/by/4.0/

\section{(c) (i) Open Access}

\begin{abstract}
As a special product, the cultivation and production of grain directly affect the consumption of people, which has an important influence on the development of social economy and the national economy and people's livelihood. Firstly, the present situation of grain production is analyzed, and the problems facing the structural reform of grain supply side in China are analyzed from grain output and its import and export volume. Secondly, we use grey GM $(1,1)$ model to predict grain output and consumption, grain import and export volume and all kinds of grain crops output in China, and then analyze the future trend of grain production in China. Finally, we put forward construction of grain branding, rational allocation of grain planting varieties, construction of traceability system for grain production, further grain processing and development of "Internet agriculture" industrial model to promote structural reform of grain supply side.
\end{abstract}

\section{Keywords}

Grain, The Structural Reform of Supply Side, Grey GM $(1,1)$ Model, Traceability System

\section{Introduction}

Agriculture as the basic industry of national economy and grain as the foundation of national economy, has the dual attributes of commodities and public goods. The quantity and form of grain production and circulation will directly affect the consumption at the end, which is deeply related to the social and economic development and the national economy and people's livelihood. Under the situation of carrying out the supply side reform, it is of great practical signi- 
ficance to study the grain problem in China. On the one hand, how to provide more alternative and effective supplies in the production and circulation of grain and how to ensure the sustainable consumption of grain in China have become an important consideration in deepening the reform of China's economic structure. On the other hand, grain as quasi-public goods, how to coordinate the interests of producers and consumers, how to guide the healthy development of production and circulation in the social market economy, is also an important consideration to adjust the relationship between the government and the market.

In recent years, with the introduction of supply side structural reform, many scholars have studied grain supply side reform from different angles. Zhang Yunsheng et al. [1] put forward some suggestions from the macro level to ensure the national food security and promote the structural reform on the supply side of agriculture. Ding Shengjun [2] analyzed the "short board" and "weakness" of grain supply side structure, and on this basis put forward the initiative of "supply side" and "demand side" work together. Under the background of "12 consecutive increases" in grain production in China, Zhang Yuejie et al. [3] analyzed the pattern of grain production and consumption in China, and proposed to adjust the grain variety structure and promote the supply side structural reform of grain industry with the goal of ensuring grain security. Zhang Chaoqun [4] made an empirical study on the formation mechanism of grain price in China by using PLS structural equation model, and put forward some suggestions for perfecting the forming mechanism of grain price market and stabilizing the grain price according to the background of the new normal state of China's economy. Li Bo [5] constructed the effect model of minimum purchase price policy for five major grain varieties, evaluated it by using double differential design and counterfactual simulation method, put forward differential pricing policy, and put forward some suggestions on the minimum purchase price policy of grain. Liu Hongwei [6], Wang Jianguo [7], Zhang Shudong [8], Xing Zhi [9], Yan Xiaoning [10], Qin Yebo [11], Yang Yongchun [12] respectively analyzed the current situation of grain supply side reform and the faced problems in Zhoukou City, Henan Province, Heilongjiang, Sichuan, Jiangsu, Jingzhou, Zhejiang, and Lingtai County, Gansu Province, and proposed the supply side structural reform measures to adapt to the local situation. Huang Zheru [13] and Zhang Changcheng [14] analyzed the brand construction of Sheyang rice and Jilin rice, and studied the significance of brand construction in promoting grain supply side structural reform.

The above scholars analyzed the current situation of grain production from different angles and study its influence on the structural reform on the supply side. Most scholars tend to study the current situation of grain production. On this basis, they analyzed the impact of grain production on supply side structural reform, but the future development of grain is less studied. This paper starts with the present situation of grain production, analyzes the problems faced by today's grain development, and uses grey GM $(1,1)$ model to predict grain out- 
put, grain import and export volume, grain crop yield. Finally, we put forward reasonable suggestions for promoting the structural reform of grain supply side.

\section{Background Description}

\subsection{Current Status of Grain Production}

There are many varieties of food crops, among which rice, wheat, corn, soybeans and potatoes are the most representative. China's grain output increased from $50,160.3$ million tons in 2007 to $61,625.0$ million tons in 2016, while per capita food consumption decreased from 138.5 kilograms in 2007 to 106.1 kilograms in 2016 [15]. People's consumption of grain decreased, indicating that the consumption of grain substitutes has increased. The function of grain as a major household item is gradually decreasing.

The income of grain planting is about 700 - 900 yuan per mu, and it takes at least 10 days to plant, spray and fertilize grain per mu. If working in cities and towns, the daily income 100 - 200 yuan, so most young workers will choose to go to the city to find work, give up the rural grain planting. Low income from grain farming has led to massive migration of people to cities and contracting out rural land. In addition, because grain is grown for two seasons and the income is low, some people will choose to change the land for growing food into greenhouse vegetables or fruits.

\subsection{Supply Side Structural Reforms}

In December 2015, the Central Economic Work Conference emphasized the promotion of supply side structural reforms and focused on the supply side structural reforms. In 2016, the Central Document No. 1 also explicitly proposed to promote structural reforms in the supply side of agriculture.

In order to promote the agricultural supply side reform effectively, farmers also need to change their concept of development in addition to the state's macroeconomic regulation and control. It is out of line with the trend of the times to apply chemical fertilizer and pesticide, and simply to pursue the production mode of yield growth. Farmers also need to adjust their planting structure, produce more green organic food, meet the changing needs of consumers, and then promote economic benefits and improve the enthusiasm of farmers to grow grain.

The main problem of China's grain existence is the "three highs" phenomenon of "high yield, high inventory, and high import". From high imports, we can find that our people do not have no demand for food, but only because of the improvement of people's living standards, brand awareness has increased, the demand for food is constantly improving. People think that imported products are of high quality and low price [16]. Therefore, they are pursuing imported products, which leads to an increase in the number of imports, and the inventory cannot be consumed. It is necessary to consume high stocks of grain in China and change people's awareness of consumption. First, we must improve the 
quality of domestic grain, and secondly, rationally process grain, change the way of grain consumed, and properly treat raw grain to change people's consumption channels.

\subsection{Traceability System}

In recent years, the government has repeatedly introduced policies and measures to emphasize agriculture and strengthen agriculture, promoting the development of agricultural information service technology, focusing on the development of technologies such as information collection, precision operations and management information, remote digitization and visualization, food safety early warning, and so on, thus continuously promoting the enterprise "production and management informatization". Using a two-dimensional code technology, RFID and other Internet of Things technology, developed a series of food safety traceability production management system, and opened a credible channel for consumers to understand the food production information, solved the problem of information asymmetry and opacity between the supply and demand sides, and safeguarded food safety [17].

"The traceable quality label referred to as 'trace source', which refers to the identification of the quality responsibility of all the actors involved in grain production, and the preservation of these labels all the time, which can be traced back to the source". "Tracing the source" is the basis of accountability for the quality responsibility of "Rest assured grain" production. The implementation of this key link makes the quality responsibility of all actors in food production clear at a glance, thus continuously monitoring all actors in food production law-abiding operation and operation according to regulations.

With the improvement of people's living standards, people's requirements for food are more strict, and the consumption of food tends to be healthy, green and environmentally friendly. Through the traceability system, the whole process of food production and processing can be presented to people, making people more assured, and enhancing people's desire for consumption.

\section{Basis of Theory and Method}

In 1982, Professor Deng Julong published "The Control Problems of Grey systems" [18], which marked the birth of the emerging discipline of the grey system theory [19]. After more than 30 years of development, the grey system theory has been applied to the fields of agriculture, economy, society and industry, solved many problems in production and life.

\section{Grey GM $(1,1)$ Model}

Grey GM $(1,1)$ model is mainly used in the prediction of grey system theory in prediction [20]. The essence of the grey GM $(1,1)$ model is that the generated data sequence has a certain quasi-exponential law by accumulating the original sequence, and the new series generated after the accumulation largely eliminates 
the randomness and instability of the original series [21]. The corresponding curve (or polyline) of the newly generated series can be approximated by an exponential function curve, and then the approximation curve is used as a model to predict the system. Grey GM $(1,1)$ model requires less data, can be tested, and has a high precision in short-term prediction. It has been widely used in many scientific fields such as industry, agriculture, energy, transportation, geology, meteorology, hydrology, ecology, environment, medicine, military, economy, society and so on, and has successfully solved a large number of practical problems in production, life and scientific research. The modeling mechanism is as follows:

Let an original sequence be:

$$
X^{(0)}=\left\{x^{(0)}(1), x^{(0)}(2), \cdots, x^{(0)}(n)\right\}
$$

Of which: $x^{(0)}(k) \geq 0, k=1,2, \cdots, n$.

Perform an accumulation (1-AGO) generation on the sequence to get the sequence:

$$
X^{(1)}=\left\{x^{(1)}(1), x^{(1)}(2), \cdots, x^{(1)}(n)\right\}
$$

$X^{(1)}$ adjacent mean generating sequence is:

$$
Z^{(1)}=\left\{z^{(1)}(2), z^{(1)}(3), \cdots, z^{(1)}(n)\right\}
$$

Of which $z^{(1)}(k)=\frac{1}{2}\left(x^{(1)}(k)+x^{(1)}(k-1)\right)$, We call

$$
x^{(0)}(k)+a z^{(1)}(k)=b
$$

the mean form of the GM $(1,1)$ model.

Let the model's parameter list be $\hat{a}=(a, b)^{\mathrm{T}}$, then use the least squares method to find

$$
\hat{a}=\left(B^{\mathrm{T}} B\right)^{-1} B^{\mathrm{T}} Y
$$

$Y, B$ of them are,

$$
Y=\left[\begin{array}{c}
y^{(0)}(2) \\
y^{(0)}(3) \\
\vdots \\
y^{(0)}(n)
\end{array}\right], \quad B=\left[\begin{array}{cc}
-z^{(1)}(2) & 1 \\
-z^{(1)}(3) & 1 \\
\vdots & \vdots \\
-z^{(1)}(n) & 1
\end{array}\right]
$$

We call

$$
\frac{\mathrm{d} x^{(1)}}{\mathrm{d} t}+a x^{(1)}=b
$$

the whitening differential equation of $x^{(0)}(k)+a z^{(1)}(k)=b$.

Then the solution of Equation (6) is

$$
\hat{x}^{(1)}(t)=\left(x^{(0)}(1)-\frac{b}{a}\right) \mathrm{e}^{-a(t-1)}+\frac{b}{a}
$$

Then the simulated prediction difference form of the original sequence is 


$$
\hat{x}^{(0)}(k)=\hat{x}^{(1)}(k)-\hat{x}^{(1)}(k-1)=\left(1-\mathrm{e}^{a}\right)\left(x^{(0)}(1)-\frac{b}{a}\right) \mathrm{e}^{-a(k-1)}
$$

In this model, $a$ is the development coefficient and $b$ is the grey effect.

\section{Status and Forecast of Grain Production}

\subsection{Grain Production and Consumption}

\subsubsection{Status of Food Production and Total Consumption}

According to the China Statistical Yearbook [15], the grain production and consumption in China from 2006 to 2016 are shown in Table 1.

Observing the data in Table 1, we can find that China's grain production shows an overall upward trend, while the total consumption shows a downward trend. The increase in output and the decrease in demand will inevitably lead to an increase in inventory, which consumes a lot of manpower and material resources. It puts a lot of pressure on the country. How to reduce inventory and change people's needs is a problem that needs to be solved urgently.

\subsubsection{Forecast of Grain Production and Total Consumption}

The grey GM $(1,1)$ model is used to forecast the grain production and consumption in 2017-2021 in China in Table 2.

Observing and forecasting data, it is found that with the improvement of agricultural mechanization level and the rationalization of planting methods, China's grain production has been increasing. In addition, with the improvement of science and technology, food substitutes are emerging, and China's grain consumption is gradually decreasing. The changing trend of grain production and consumption leads to the increase in inventories, which is a big problem that needs to be solved urgently.

\subsection{Cereals Imports and Exports}

\subsubsection{Status of Cereals Import and Export}

This paper mainly analyzes the major grain crops. From the China Statistical

Table $1^{1}$. Grain production and consumption in China in 2006-2016. (Unit: kg).

\begin{tabular}{cccccccccccc}
\hline & 2006 & 2007 & 2008 & 2009 & 2010 & 2011 & 2012 & 2013 & 2014 & 2015 & 2016 \\
\hline $\begin{array}{c}\text { Grain } \\
\text { yield }\end{array}$ & $49,747,900$ & $50,160,300$ & $52,870,900$ & $53,082,100$ & $54,647,700$ & $57,120,800$ & $58,958,000$ & $60,193,008$ & $60,702,006$ & $62,143,900$ & $61,625,000$ \\
$\begin{array}{c}\text { Total grain } \\
\text { consumption }\end{array}$ & $18,503,935.0$ & $18,299,866.5$ & $18,180,593.8$ & $18,055,785$ & $17,632,966.5$ & $16,936,189.5$ & $16,451,586$ & $15,961,245.6$ & $15,251,193$ & $14,804,657.414,670,553.1$ \\
\hline
\end{tabular}

Table 2. Forecast values of grain production and consumption in China in 2017-2021. (Unit: kg).

\begin{tabular}{ccccc}
\hline & 2017 & 2018 & 2019 & 2020 \\
Grain production & $62,170,608.67$ & $62,368,271.42$ & $62,566,562.60$ & $62,765,484.22$ \\
Total grain consumption & $14,492,635.97$ & $14,390,224.87$ & $14,288,537.46$ & $14,187,568.61$ \\
\hline
\end{tabular}

${ }^{1}$ Source: China statistical yearbook. 
Yearbook [20], the import and export of cereals imports in China from 2006 to 2016 is shown in Table 3. The data can be used to increase the growth rate of each year.

From Table 3, it is found that before 2007, China's cereals imports imports were lower than exports. After 2007, China's cereals imports imports were higher than exports and imports increased rapidly year by year. According to the data in the table, China's cereals imports imports have been increasing and increasing sharply except in 2016, while the export volume [22] of cereals imports has been decreasing except in 2013 and 2016. The increase in imports and the decrease in exports put great pressure on China's cereals imports stocks. At the same time, the increase in imports has led to capital outflows and reduced foreign exchange reserves.

\subsubsection{Forecast of Grain Imports and Exports}

The grey GM $(1,1)$ model is used to predict the import and export of China's cereals imports in 2017-2021 as shown in Table 4.

By observing the forecast values, we can find that the export volume of China's cereals is still gradually declining, and the import volume is increasing year by year. The export volume is decreasing year by year, and the increasing import

Table $3^{2}$. China's cereals import and export volume and its growth rate in 2006-2016. (Unit: 100 million US dollars).

\begin{tabular}{|c|c|c|c|c|c|c|c|c|c|c|c|}
\hline & 2006 & 2007 & 2008 & 2009 & 2010 & 2011 & 2012 & 2013 & 2014 & 2015 & 2016 \\
\hline $\begin{array}{l}\text { Cereals } \\
\text { exports }\end{array}$ & 8.07 & 7.33 & 6.73 & 6.13 & 5.39 & 6.09 & 4.43 & 5.14 & 4.45 & 3.22 & 4.29 \\
\hline $\begin{array}{l}\text { Growth } \\
\text { rate of } \\
\text { cereals } \\
\text { exports }\end{array}$ & & -0.09 & -0.08 & -0.09 & -0.12 & 0.13 & -0.27 & 0.16 & -0.13 & -0.28 & 0.33 \\
\hline $\begin{array}{l}\text { Cereals } \\
\text { import }\end{array}$ & 3.45 & 5.22 & 6.99 & 8.76 & 15.01 & 20.16 & 47.51 & 50.54 & 61.75 & 93.48 & 56.61 \\
\hline $\begin{array}{l}\text { Growth } \\
\text { rate of } \\
\text { cereals } \\
\text { import }\end{array}$ & & 0.51 & 0.34 & 0.25 & 0.71 & 0.34 & 1.36 & 0.06 & 0.22 & 0.51 & -0.39 \\
\hline
\end{tabular}

Table 4. Forecast of China's cereals import and export volume in 2017-2021. (Unit: 100 million US dollars).

\begin{tabular}{lccccc}
\hline & 2017 & 2018 & 2019 & 2020 & 2021 \\
\hline Cereals export & 3.99 & 3.90 & 3.86 & 3.86 & 3.82 \\
Cereals import & 66.17 & 66.93 & 67.70 & 68.47 & 69.26 \\
\hline
\end{tabular}

${ }^{2}$ Source: China statistical yearbook. 
volume will continue to increase the inventory of China's cereals. Therefore, changing people's consumption concept, improving grain quality, expanding exports, and controlling imports is the important aspect of the current food supply side reform.

\subsection{Grain Planting Structure}

\subsubsection{Status of Production of Various Food Crops}

According to the China Statistical Yearbook [20], China's various grain production in 2006-2016 is shown in Table 5.

Table 5 shows that the growth of cereals (rice, wheat, maize) in China is relatively stable, while the yield of beans and potato is fluctuating, and there has been a sharp decline between 2006 and 2007. In fact, the production of beans and potato decreased, but the consumption demand increased year by year, which led to the increase of imports of beans and potato. Corn and other cereals production continues to grow, but the market demand has not increased. In addition, the import quantity of cereals is increasing. The imbalance of supply and demand actually reflects the unreasonable planting structure. Therefore, our country needs to arrange the planting of grain reasonably in order to meet the changing demand of the market.

\subsubsection{Forecast of Production of Various Grain Crops}

The grey GM $(1,1)$ model is used to predict the grain crop production in China from 2017-2021 as shown in Table 6.

Table 6 shows that the yield of all kinds of grain crops in China increased year by year in 2017-2021, and the increase of cereals was more than that of beans and potato. This aspect is affected by scale planting and people's mentality, cereals planting area is larger. At the same time, people are not aware of the market demand for beans and potato, so they have not yet changed their cultivation strategies, resulting in continued growth in cereals production.

Table $5^{3}$. Production of various grain crops in China in 2006-2016. (Unit: 10,000 tons).

\begin{tabular}{cccccccccccc}
\hline & $\mathbf{2 0 0 6}$ & $\mathbf{2 0 0 7}$ & $\mathbf{2 0 0 8}$ & $\mathbf{2 0 0 9}$ & $\mathbf{2 0 1 0}$ & $\mathbf{2 0 1 1}$ & $\mathbf{2 0 1 2}$ & $\mathbf{2 0 1 3}$ & $\mathbf{2 0 1 4}$ & $\mathbf{2 0 1 5}$ & $\mathbf{2 0 1 6}$ \\
\hline Cereals & $44,237.3$ & $45,632.4$ & $47,847.4$ & $48,156.3$ & $49,637.1$ & $51,939.4$ & $53,934.7$ & $55,269.2$ & $55,740.7$ & $57,228.1$ & $56,538.1$ \\
Beans & 2104.5 & 1720.1 & 2043.3 & 1930.3 & 1896.5 & 1908.4 & 1730.5 & 1595.3 & 1625.5 & 1589.8 & 1730.8 \\
Potato & 3406.1 & 2807.8 & 2980.2 & 2995.5 & 3114.1 & 3273.0 & 3292.8 & 3329.3 & 3336.4 & 3326.1 & 3356.2 \\
\hline
\end{tabular}

Table 6. Forecast of the production of various grain crops in China in 2017-2021. (Unit: kg).

\begin{tabular}{cccccc}
\hline & $\mathbf{2 0 1 7}$ & $\mathbf{2 0 1 8}$ & $\mathbf{2 0 1 9}$ & $\mathbf{2 0 2 0}$ & $\mathbf{2 0 2 1}$ \\
\hline Cereals & $57,112.52$ & $57,303.47$ & $57,495.05$ & $57,687.28$ & $57,880.15$ \\
Beans & 1692.58 & 1693.35 & 1694.13 & 1694.90 & 1695.67 \\
Potato & 3365.50 & 3371.49 & 3377.49 & 3383.49 & 3389.51 \\
\hline
\end{tabular}

${ }^{3}$ Source: China statistical yearbook. 


\section{Policy Recommendations}

\subsection{Grain Branding}

Brand is an important indicator that people pay attention to, through establishing grain brand, people can have a clearer understanding of grain in various places, thus increase people's consumption. The main reason why Chinese people choose to buy some foreign products is that their brand effectiveness is more obvious. China can also promote the consumption of domestic food by establishing brands for local food.

\subsection{Deep Processing of Grain Production}

Through the deep processing of raw grain, the grain will be converted into other products to promote people's consumption. At the same time, the government can establish some grain processing plants in areas with more concentrated grain production based on the setting of grain protection price. On the one hand, it can promote the conversion of raw grain. On the other hand, it can also solve the local employment problem, prompt people to stay in the countryside to grow grain, avoid arable land idle, and at the same time help promote China's grain branding.

\subsection{Adjustment of Grain Planting Structure and Large-Scale Cultivation}

The production of China's cereals is relatively high and the output of beans and potato is low. The export volume of grain is in a state of decline, which leads to the inventory of grain. The demand for beans and potato in China is strong, but the production is insufficient, resulting in a large number of imports. Therefore, China can promote farmers to grow beans and potato through policy support, and appropriately reduce the cultivation of cereals. On the one hand, it can consume the stock of cereals, on the other hand, it can meet people's needs and reduce the import of beans and potato.

\subsection{Establishment of Traceability System for Food Production and Processing}

With the fermentation of "poisonous wheat" and "Sanlu milk powder" incidents, and the development of science and technology, people pay more attention to food safety. People want to buy some green, safe, healthy food, want to check the quality of the product from the source. In order to meet the needs of the people, we can establish a grain production traceability system, so that people can see the whole process of the production and processing of the products they purchase, so that people can be more assured with the grain of our country, thus promoting people's consumption.

\subsection{Development of the "Internet + Agriculture" Industry Model}

The concept of the "Internet+" has been developed in different fields since it was 
put forward. In the field of agricultural production, rural Taobao, JingDong and other third-party e-commerce platforms can be used to set up village-level network flagship stores, relying on rural e-commerce online stores to sell small grains and local specialty products on the Internet. Actively research and development of small grains and grain processing products suitable for net sales. Strictly control the quality of products, and design exquisite packaging to meet people's different needs. By constructing "Internet + Agriculture" industrial model can expand the sales channels of agricultural products, thereby increasing consumption.

\section{Conclusion}

In this paper, the problems of grain supply side structural reform in China are analyzed, the present situation of grain production in China is analyzed, and the grey GM $(1,1)$ model is used to forecast all kinds of grain and related consumer goods in China. By analyzing the present situation and forecasting results, it is found that there are some problems in China's grain production. The grain production is high but the consumption is low, the cereals import quantity is bigger but the export quantity is smaller, the cereals production is high and the beans and potato production is low, but the beans and potato demand is large. In order to promote structural reform on the grain supply side, grain production can be adjusted from the following aspects: Branding grain, improving food quality, expanding the influence of grain; deep processing grain to promote consumption of grain and related products; adjusting grain planting structure, expanding cultivation of beans and potato; establishing food traceability system, overseeing the whole process of grain production and processing by consumers; carrying out the "Internet + agriculture" industry model, broadening the sales channels of agricultural products. Accurately grasping the problems faced by China's grain production is the key to promoting structural reform of the grain supply side. Promoting the structural reform of the grain supply side is of great significance to safeguarding national food security.

\section{Acknowledgements}

The authors are grateful to anonymous referees for their helpful and constructive comments on this paper. The work is supported by the Soft-science Foundation of Henan Province (172400410015), and the Philosophy and Social Program of Henan Province (2016BJJ022).

\section{Conflicts of Interest}

The authors declare no conflicts of interest regarding the publication of this paper.

\section{References}

[1] Zhang, Y.S. and Liu, J.Q. (2016) Suggestions on the Structural Reform of Agricul- 
tural Supply Side Based on the Macro Level. Crop Research, 30, 617-618+638.

[2] Ding, S.J. (2016) The Thinking of Grain Supply Side Reform as the Main Line, and Synchronous Force on Both Sides. Price: Theory \& Practice, No. 1, 23-25+55.

[3] Zhang, Y.J. and Wang, J. (2017) Difficulties in Promoting the Supply-Side Structural Reform of Grain Industry and Countermeasures. Economic Review, No. 2, 110-114.

[4] Zhang, C.Q. and Wang, L.Q. (2016) Research on the Formation Mechanism of Grain Price under the Reform of Supply Side Structure in China-An Empirical Analysis Based on PLS Structural Equation Model. Price: Theory \& Practice, No. 12, 45-48.

[5] Li, B. (2016) Research on the Effect and Evaluation of China's Minimum Grain Purchase Price Policy. Price: Theory \& Practice, No. 11, 70-73.

[6] Liu, H.W., Li, F. and Zhan, H. (2016) Zhoukou City, Henan Province: Actively Exploring the Reform of Grain Supply Side in Plain Wheat Region. China Grain Economy, No. 8, 46-48.

[7] Wang, J.G. (2016) Promote Agricultural Supply Side Reform, Vigorously Build High Standard Farmland. China Economic \& Trade Herald, No. 10, 64-65.

[8] Zhang, S.D. (2017) Thoughts on Promoting the Structural Reform of Sichuan Grain Supply Side to a New Level. Grain Issues Research, No. 4, 4-8.

[9] Xing, Z. (2017) Thoughts on the Structural Reform Practice of Jiangsu Grain Supply Side. Modern Flour Milling Industry, No. 3, 34-38.

[10] Yan, X.N. (2017) Targeting Three Major Areas to Promote Structural Reform of the Food Supply Side. China Economic \& Trade Herald, No. 27, 46-46.

[11] Qin, Y.B., Lin, B.Y. and Ji, G.C. (2018) Thoughts and Suggestions on the Reform of Supply Side of Grain Production in Zhejiang Province. Journal of Zhejiang Agricultural Sciences, No. 3, 360-362, 369.

[12] Yang, Y.C. (2018) Thoughts on the Reform of Grain Supply Side Structure-Taking Lingtai County of Gansu Province as an Example. Productivity Research, No. 7, 51-54.

[13] Huang, Z.R., Zhou, Z.K., Cheng, Z.T., et al. (2017) Bigger and Stronger "Shenyang Rice" Brand, Boosting the Structural Reform of Food Supply Side. Barley and Cereals Sciences, 34, 62-64+66.

[14] Zhang, C.C. (2017) Creating the Core Brand of "Jilin Rice" to Promote Structural Reform of Food Supply Side. China Grain Economy, No. 5, 25-27.

[15] National Bureau of Statistics (2017) China Statistical Yearbook. China Publishing House, Beijing.

[16] Raissi, M. and Tulin, V. (2017) Price and Income Elasticity of Indian Exports-The Role of Supply Side Bottlenecks. Quarterly Review of Economics and Finance, 68, 39-45.

[17] Hou, J.H. and Sun, J. (2017) Ideas and Countermeasures Concerning the Structural Reforms of the Food Supply Side. Journal of Huaiyin Institute of Technology, 26, 52-56.

[18] Deng, J.L. (1982) Control Problem of Grey System. System \& Control Letter, 1, 288-294. https://doi.org/10.1016/S0167-6911(82)80025-X

[19] Deng, J.L. (1988) Grey Forecasting and Decision Making. Huazhong University of Science and Technology Press, Wuhan.

[20] Liu, S.F., et al. (2015) Grey System Theory and Its Application. Science Press, Bei- 
jing.

[21] Tang, Y.C., Shen, M.X. and Zhang, D.L. (2003) A Problem Noticed in Building Model of Grey System. Systems Engineering and Electronics, No. 3, 302-303.

[22] Huang, J.K., Wei, W., Cui, Q., et al. (2017) The Prospects for China's Food Security and Imports: Will China Starve the World via Imports? Journal of Integrative Agriculture, No. 12, 2933-2944. https://doi.org/10.1016/S2095-3119(17)61756-8 